\title{
Stress Coping Strategies among College Students: A Case in the College of Education, Eritrea Institute of Technology
}

\author{
Dawit Yikealo $^{1 *}$, Werede Tareke ${ }^{1}$ \\ ${ }^{1}$ Eritrea Institute of Technology, Eritrea \\ *Corresponding author:Dawit Yikealo: dawityikealo@gmail.com
}

\section{OPEN ACCESS}

Citation: Yikealo D., Tareke W. (2018) Stress Coping Strategies among College Students: A Case in the College of Education Eritrea Institute of Technology.Open Science Journal 3(3).

Received: $7^{\text {th }}$ May 2018

Accepted: $23^{\text {rd }}$ July 2018

Published: $18^{\text {th }}$ September 2018

Copyright:@ 2018 This is an open access article under the terms of the Creative Commons Attribution License, which permits unrestricted use, distribution, and reproduction in any medium, provided the original author and source are credited.

Funding: The author(s) received no specific funding for this work

Competing Interests: The author have declared that no competing interests exists.

\section{Abstract:}

The study was intended to investigate the stress coping strategies among College of Education (CoE) students in Eritrea Institute of Technology, Mainefhi. To investigate the students' stress coping strategies, descriptive research was carried out among a total of 123 students participants who were randomly drawn from the CoE. A self-developed College Students Coping Strategies Scale which entails 15 items has been utilized. The results of the study presented that the students were found to use more positive stress coping strategies than the negative ones. An independent-sample t-test result indicated that there is no statistically significant relationship between gender and both positive and negative stress coping strategies. The study is expected to have an impact on broadening the horizon of knowledge and understanding of stress coping strategies practiced by the $\mathrm{CoE}$ students. The study will support the college students to identify the positive and negative coping strategies, thereby stick to the healthy ones.

Keywords: Stress, Stress coping strategies, College students

\section{Introduction}

Stress is an essential and inevitable part of daily living because, without some stress, we would be listless and apathetic creatures. Stress is unavoidable because it relates to any external event which may be pleasurable or threatening. A 
person's reaction towards stress relays on whether an event is evaluated as a challenge or a threat (Lazarus \& Folkman, 1984). Challenging situations can lead to positive outcomes such as motivation and improved task performance (Rheinberg \& Engeser, 2018) while threatening ones or distress can result in anxiety, depression, social dysfunction and even suicidal intention (Tang, Byrne, \& Qin, 2018). Along with the enhancements during the scientific era and the speedy development of information, competitiveness among people has become increasingly robust, as a consequence, people have become busy and demanding, and thus, stress is a natural consequence. Albeit appropriate stress is a juncture for self - growth, it is also a drive for people to headway keenly. It not merely affects our thoughts and feelings but our actions as well. However, overstress causes problems and discomfort, and can have severe effects on people. Precisely, students face stress when they enter an entirely new world of the education professionals.

Stress is continuously observed as a psychological process that encompasses an individual's perception and response to any intimidating event. It is significant to note that stress can have both positive and negative effects on people. It means that stress may be a healthy, adaptive reaction to an event perceived as a threat. Its role is to awaken and prepare individuals to take defensive action. Take, for instance, fear of things that present realistic threats motivates individuals to deal with them or avoid them. Most psychologists assert that moderate stress motivates individuals to achieve and fuels creativity, although stress may hinder individuals from performance on difficult tasks (Auerbach \& Gramling, 1998). What this essentially indicates is that even though average level of stress is supportive, a higher level of stress can lead to exacerbating mental health problems if it is not managed effectively (Coiro, Bettis, \& Compas, 2017). Additionally, when a person is exposed to chronic stress, she or he is likely to experience both physical illnesses (including heart disease), and mental illness (e.g., anxiety disorders).

Due to the detrimental impact of stress on health, individuals engage in different coping styles to deal with stressors. Coping, is, therefore, defined as an array of conscious behaviors and mental efforts employed to deal with a stressful event or the situation with the aim of minimizing its negative consequence (Lazarus \& Folkman, 1984). Coping involves specific cognitive evaluation of whether an individual believes that he or she is capable of handling the stressful situation. Coping can takes different forms such emotion-focused coping in which individuals focus on reducing the adverse emotional reaction, and problemfocused coping in which the focus is on finding out a practical ways of solving stressful situation (Lazarus \& Folkman, 1984), also described as active and passive (Jex, Bliese, Buzzell, \& Primeau, 2001) or approach and avoidance (Anshel, 1996) stress coping styles.

\section{Statement of the problem}

The transition from high schools to college level could cause psychological, academic, and social shock to students since this educational level has pronounced differences: the student will face new method of teaching, new 
academic requirements, new types of relations between students and faculties, new living environment (feeding and dwelling in mass).

Due to these changes, students can potentially experience different types of stress that can affect their mental and social health and academic achievement. Students of this level can be encountered with academic stressors like tests, assignments, projects and other college requirements. The inability as well as the shortcomings to fulfill these requirements leaves students to get stressed. The physical environment including the location, buildings with its teaching and learning equipment, transportation access and other services provided on the campus for students can aggravate students stress levels. The social wellbeing is also a determinant factor for active learning. The social setting and its complexity: a large number of population, the pressures from peers and the nature of the interpersonal social interactions, the intolerable misbehaving of others and sexual relationship affairs are influential for the social well-being of the learners (Coiro et al., 2017; Garthe et al., 2017).

Similarly, stress affects the psychological and physical health of students. For instance, students with high levels of stress tend to perceive themselves as less healthy, with low self-esteem (Chen et al., 2017) and are more prone to practice some health risk habits (Pelletier, Lytle, \& Laska, 2015). According to stress and coping theory of Lazarus and Folkman (1984) individuals are prone to psychopathological experience primarily in the absence of healthy coping strategies. Thus, it has been felt that conducting an empirical study to discover and understand the nature of the coping strategies that college students use to deal with their campus stress is necessary and momentous.

\section{Review of Literature}

Research studies documented that the prevalence of stress has recently been growing among students in higher education (Kadhiravan \& Kumar, 2012; Robotham \& Julian, 2006). Given this, some researchers have been concerned with the type of coping strategies that college students use to cope with the stressful situation. Several studies have reported that students often use poor coping strategies like drinking alcohol, smoking, and using illegal drugs (Pierceall \& Keim, 2007). Students differ concerning their appraisal of the stressor, causal attribution, preoccupation, feelings and actions to cope with stressors (SeiffgeKrenke, Weidemann, Fentner, Aegenheister, \& Poeblau, 2001). Use of coping skills such as cognitive reinterpretation and problem-solving may promote better health and adaptation in students of higher education (Sasaki \& Yamasaki, 2007). There is an increasing evidence that leads us to believe that young people who can at least make an effort to regulate negative emotions will be less vulnerable to reacting to stress with inappropriate behaviors (Pardini, Lochman, \& Wells, 2004).

As cited by Kadhiravan and Kumar (2012), Kelly and Louise (2007) indicated that proactive coping does influence the likelihood of stress-related growth. Self-efficacy theory of Bandura (1997) is an essential prerequisite for changing coping behavior. Receiving elaborative feedbacks promote students selfefficacy while receiving knowledge of correct response improved students' 
performance. High self-efficacious students applied high-level learning strategies, such as elaborative strategies and critical thinking (Wang \& Wu, 2008). Proper intervention programmes enhance the proactive coping competencies significantly (Bode, de Ridder, Kuijer, \& Bensing, 2007). Students participating in coping enhancement-training programme displayed better individual coping skills after the training, and they relied upon dysfunctional coping strategies less often even after two years (Bodenmann, Perrez, Cina, \& Widmer, 2002). A five-session programme, including psychoeducation, group discussion, role-playing and relaxation training might be useful in enhancing coping skills, increasing social support, and reducing stress responses (Shimazu, Okada, Sakamoto, \& Miura, 2003)

In a study carried out by Honglin, Yu-Cheung, Mao-Sheng, and Christie (2009), psychological well-being was found to be negatively connected to college stress and stress coping strategies significantly moderated the relationship between college stress mental health. Also, they found that the male students accounted for the elevated level of stress, inferior mental well-being, and having fewer proclivities towards using positive coping strategies as compared to female students. Apart from this, Adam and Epel (2007) found that persons who overeat as a means of dealing with stress use food to activate their physiological reward system; they continue to use this strategy because they begin to feel good. However, overeating may not be an effective coping strategy as it can also lead to health risks associated with obesity (Chenji, Rao, Sivanesan, Kamath, \& Kamath, 2018).

Men may have different ways of coping with stress (Misra \& Castillo, 2004). For example, Matud (2004) and Brougham, Zail, Mendoza, and Miller (2009) found that women's stress coping strategies are emotion-oriented and tend to display their feelings more overtly/openly whereas men are more likely to inhibit their emotional reaction to stress. Fox (2004) also noted that women are more likely to engage in crying as a stress relief mechanism and noted that crying could be healing, releasing, and stress-busting

Bottorff, Johnson, Moffat, and Mulvogue (2009) found that adolescent students use substance abuse like marijuana for stress relief although marijuana use was the critical contributing factor to undesirable health consequences (Allen \& Holder, 2014). The consumption of marijuana was also found to be greater in males than females (Allen \& Holder, 2014). Similarly, in a very recent report, heavy and frequent alcohol consumption was found to worsen college students' mental health problems such poor memory power and concentration (Meda et al., 2018), anxiety and depression (Bewick et al., 2008; Kenney, DiGuiseppi, Meisel, Balestrieri, \& Barnett, 2018; Lorant, Nicaise, Soto, \& d'Hoore, 2013).

There is a lack of accord about the impact of gender on negative coping strategies. Honglin et al. (2009) found that males are more likely to use negative coping strategies such as alcohol consumption and drug use (Misigo, 2015). Dyson and Renk (2006), on the other hand, found that regardless of gender, students use similar negative coping strategies - such as alcohol consumption. Students may also misuse sleeping pills (Zafar et al., 2008) or prescription stimulants (Allen \& Holder, 2014) in order to combat daytime fatigue and sleepiness (Waqas, Khan, Sharif, Khalid, \& Ali, 2015) in an effort to derive better focus, concentration and well-being (Weyandt et al., 2009). 
Generally, an excellent social network buffers stress (Macgeorge, Samter, \& Gillihan, 2005) and is comprised of any interpersonal connection which can include face-to-face interactions and online socialization. Good friends can increase resilience and decrease stress encountered at university (Singh, 2016). Friend support plays a protective role with resilience amid an environment of academic stress. However, both part-time and full-time students may reduce their social and non-academic activities to cope with their studies, which according to Gaedke, Covarrubias Venegas, Simbrunner, and Janous (2012) is counterproductive since socialization acts as a stress buffer. Besides, the research explored religious coping strategy such as prayer commonly practiced by many people. For example, Qidwai, Tabassum, Hanif, and Khan (2009) discovered that prayer is a common strategy that individuals use to cope with stress and maintain good holistic health. In the same way, personal religious involvement, particularly the frequency of attendance at religious services was found to positively associated good health and inversely associated distress (Ellison, Boardman, Williams, \& Jackson, 2001) and act as buffers against stress and beneficial for upholding life satisfaction (Fabricatore, Handal, \& Fenzel, 2012).

\section{Purpose of the study}

The primary purpose of the study was to identify the common coping strategies that college of education students use to deal with their feeling of stress.

\section{Research questions}

1. What are the typical positive stress coping strategies in the college of education students?

2. What are the typical negative stress coping strategies in the college of education students?

3. Is there any difference in positive coping strategy between male and female students?

4. Is there any difference in negative coping strategy between male and female students?

\section{Methods}

\section{Research Design}

The research group adopted the study with the help of descriptive research design. The required quantitative data were collected using the survey method.

\section{Participants}

In this study, a total of 123 students of $2 \mathrm{nd}$, 3rd, and 4th year of degree and diploma program were recruited. The sample was comprised of participants from all the six departments of the college. To draw the sample, random sampling strategy was applied. In obtaining the required sample number, the investigators 
took the demographic variables like gender, program (Degree/Diploma), grade point average (GPA), department, and year of study into account.

\section{Measure}

A 15 item self-report questionnaire was employed to measure stress coping strategy. The items of the instrument used in the study were self-developed. We prepared the questionnaire based on previous literature. To ensure the validity of the instrument, the questionnaire was reviewed by four experts from the college of education.

\section{Procedure}

The research was conducted by distributing the questionnaires to the selected number of participants from each department in the college of education. As the level of education was known to understand the English language, the questionnaire was used with no translation to another language. Thus, the questionnaire was easily administered by the participants. However, to avoid some difficulties, the research group was present at the time and place of distributing questionnaires. To facilitate the data collection, researchers assisted by some faculty member from the college. The questionnaires were distributed among participants in different classrooms at the same time. In collecting the data, all the necessary research ethics were taken into consideration.

\section{Data Analytical Procedure}

As the principal purpose of the study was to describe the typical coping strategies (both healthy and unhealthy) in the college of education students, frequency distribution and descriptive statistics (mean and standard deviation) were used to summarize the data. To determine the relationship between coping strategies and gender, an independent-sample t-test was calculated.

\section{Reliability Analysis}

As presented in table 1, the alpha coefficient for positive stress coping strategies is 0.603 , and negative stress coping strategies is 0.743 . This value indicates that the data obtained using this instrument is reliable.

Table 1: Coefficient alpha values for positive and negative stress coping strategies

Scale Cronbach's Alpha $\quad$ Number of items

Positive stress coping strategies

Negative stress coping strategies
.603

10

.743
5 


\section{Results}

\section{Distribution of the scores of the Data}

To assess the assumption of normality for the study variables, measures of distribution shape, skewness and kurtosis were calculated. The statistical values for skewness and kurtosis between -2 and +2 are considered as acceptable limits to prove the normal univariate distribution (Field, 2009; Gravetter \& Wallnau, 2014). Therefore, as depicted in table 3, the values of skewness and kurtosis for the study variables fell within the acceptable range, reflecting that data were normality distributed.

Table 2: Summary of Descriptive statistics of stress coping strategies

\begin{tabular}{lccccc}
\hline Positive coping strategies & N & M & SD & Skewness & Kurtosis \\
\hline Positive & 123 & 26.61 & 5.04 & -.37 & -.28 \\
Negative & 123 & 7.21 & 2.84 & 1.21 & 1.36 \\
\end{tabular}

\section{Descriptive statistics for positive coping strategies}

Table 3 presented the rank of the ten positive stress coping strategies based on the mean and standard deviation values. The first top three coping strategies were found to be sleeping and taking enough rest, removing oneself from the stressful situation and chatting with friends. On the other hand, contacting a professional like a psychologist or a counselor, doing regular exercise and making oneself busy with academic activities were found to be the least coping styles used by the college students.

Table 3: Summary of descriptive statistics for positive coping strategies

\begin{tabular}{llcc}
\hline Positive coping items & N & M & SD \\
\hline Sleeping and taking enough rest & 123 & 3.15 & .97 \\
Removing oneself from the stressful situation & 123 & 3.14 & .95 \\
Chatting with friends & 123 & 3.12 & 1.03 \\
Watching movies and entertaining comedies & 123 & 3.09 & 1.03 \\
Prayer, reading religious scripts, listening spiritual songs & 123 & 3.06 & .99 \\
Sharing one's problem with parents, friends, and teachers & 123 & 2.87 & 1.05 \\
Learning how to manage time properly & 123 & 2.73 & 1.00 \\
Making oneself busy with academic activities & 123 & 2.38 & 1.01 \\
Doing regular exercise & 123 & 2.21 & 1.08 \\
Contacting professionals like psychologists or counselors & 123 & 1.64 & 1.00
\end{tabular}




\section{Frequency distribution of participants' response for each item}

To identify the specific positive stress coping strategies practiced by the students, a frequency distribution analysis for each coping technique was computed as presented in the table below (table 4). The frequency distribution was expressed in the form of a proportion of the participants who responded to each point of the four liker scale (never, sometimes, frequently and always).

Table 4: Frequency distribution of the positive coping strategies

\begin{tabular}{lcccc}
\hline Stress Coping strategy & Never (\%) & $\begin{array}{l}\text { Rarely } \\
(\mathbf{\%})\end{array}$ & $\begin{array}{l}\text { Sometimes } \\
(\mathbf{\%})\end{array}$ & $\begin{array}{l}\text { Frequently } \\
(\mathbf{\%})\end{array}$ \\
\hline Doing regular exercise & $33.2 \%$ & $28.5 \%$ & $22.0 \%$ & $16.3 \%$ \\
Watching movies and entertaining comedies & $11.4 \%$ & $14.6 \%$ & $27.6 \%$ & $46.4 \%$ \\
Chatting with my friends & $11.4 \%$ & $13.0 \%$ & $27.6 \%$ & $48.0 \%$ \\
Contacting professionals (e.g. counselor) & $64.2 \%$ & $17.9 \%$ & $7.3 \%$ & $10.6 \%$ \\
Making oneself busy with academic activities & $23.6 \%$ & $30.1 \%$ & $30.9 \%$ & $15.4 \%$ \\
Sharing my problem with parents, friends, and & $13.8 \%$ & $19.5 \%$ & $30.9 \%$ & $35.8 \%$ \\
teachers & & $19.5 \%$ & $27.6 \%$ & $46.4 \%$ \\
Removing oneself from the stressful situation & $6.5 \%$ & $17.1 \%$ & $30.9 \%$ & $42.2 \%$ \\
Prayer, reading religious scripts & $9.8 \%$ & $27.6 \%$ & $32.6 \%$ & $26.8 \%$ \\
Learning to manage time properly & $13.0 \%$ & $17.9 \%$ & $26.8 \%$ & $48.0 \%$ \\
Sleeping and taking enough rest & $7.3 \%$ & &
\end{tabular}

As presented in table 4, the frequency of distribution for participants' responses on the Likert scale of each coping technique is described one by one as follow. (1) Doing regular exercise: the first item was about how often the students use regular exercise to deal with their feeling of stress. Majority of the students were found $33.2 \%$ (never) and $28.4 \%$ (rarely) practice doing regular exercise. The rest of them responded that $22 \%$ (sometimes) and $16.3 \%$ (frequently) do regular exercise. Therefore, this indicates that doing regular exercise which is, in fact, one of the successful stress managing strategies is not a commonly practiced technique among the college of education students. (2) Watching movies and entertaining comedies: on this coping strategy, a high percentage of the respondents $(46.4 \%)$ were found to use this technique to deal with their stress level frequently. The rest of them have said that 27.6\% (sometimes), $14.6 \%$ (rarely) and $11.4 \%$ (never) practice this strategy. Therefore, it can be inferred that watching movies and comedies is one of the commonly practiced stress coping strategies among the college of education students. (3) Chatting with friends: with this respect, a high percentage of the students (48\%) frequently chat 
with their friends when they feel stressed. $27.6 \%$ of the participants have also reported that they sometimes chat with their friends to deal with their feeling of stress. However, a small percentage of the participants were also found never and rarely practice chatting with friends as a stress coping mechanism. (4) Meeting professionals like counselors: as indicated in table 4, a higher number of participants $(64.2 \%)$ have reported that they never meet or contact professionals when they feel stressed. The rest of them have said that they rarely $(17.9 \%)$, sometimes $(7.3 \%)$ and frequently $(10.6 \%)$ meet and seek help from professionals like counselors. (5) Making oneself busy with academic activities: The participants towards this item responded that $30.9 \%$ (sometimes) and $15.4 \%$ (frequently) practice this technique to manage their feeling of stress. Conversely, the rest of the participants have reported that they never $(23.6 \%)$ and rarely (30.1\%) make themselves academically busy to cope with their feeling of stress. (6) Sharing the problem with parents friends or teachers: Many of the participants $(35.8 \%)$ have responded that they most of the timeshare their problem with their friends, parents, and teachers as a stress coping mechanism. The remaining respondents have also said that they sometimes (30.9\%), rarely $(15.5 \%)$, and never (13.8\%) practice this stress coping strategy. (7) Removing oneself from the stressful situation: on this item, the majority of the participants (46.4\%) were found practicing this stress coping strategy frequently. $27.6 \%$ have also said they sometimes use this technique. The rest of the participants, however, rarely $(19.5 \%)$ and never $(6.5 \%)$ remove themselves from the stressful situation. (8) Prayer: the result on this item presents that a high percentage of the respondents (42.2\%) most of the time and $30.9 \%$ (sometimes) pray, read spiritual scripts and listen to the spiritual song to cope their feeling of stress. The other participants have informed that they rarely $(17.1 \%)$ and never $(9.9 \%)$. (9) Learning to manage time properly: $26.8 \%$ of the respondents have reported that they frequently learn to budget their time wisely to minimize their feeling of stress. $32.6 \%$ have also said they sometimes use stress coping mechanism. Conversely, the rest of the respondents have asserted that they never (13\%) and rarely $(27.6 \%)$ practice learning to administer their time prudently to deal with their feeling of stress. Therefore, this result points out the college of education students do not frequently practice effective time management. (10) Sleeping and taking enough rest: a high percentage of the respondents (48\%) were found practicing this stress coping mechanism most frequently. Besides, some of the participants $(26.8 \%)$ have reported that they sometimes sleep and take enough rest when they feel stressed. On the other hand, the other participants were found never $(7.3 \%)$ and rarely $(17.9 \%)$ sleep and take enough rest to cope with their feeling of stress.

\section{Descriptive statistics for Negative coping strategies}

As it is presented in table 5, eating much and getting angry and yelling at other people appeared to be the first top two negative stress coping strategies utilized by some students to deal with a stressful situation. Smoking cigarette was found to be the least one. 
Table 5: Summary of mean and standard deviation values for negative coping strategies

\begin{tabular}{lccc} 
Negative coping strategies items & N & M & Sd \\
\hline Eating much. & 123 & 1.66 & .91 \\
Getting irritable and yell at others. & 123 & 1.65 & .90 \\
Taking alcohol. & 123 & 1.40 & .84 \\
Joining to the nightclub and make fun. & 123 & 1.34 & .74 \\
Smoking cigarette. & 123 & 1.17 & .62 \\
\hline
\end{tabular}

\section{Frequency distribution for negative stress coping strategies}

To describe the percentage of the students' use of negative stress coping strategies, a frequency distribution for each item was computed and presented in the table below.

Table 6: Frequency distribution of the negative coping strategies

\begin{tabular}{lcccc}
\hline Stress coping strategy & Never (\%) & $\begin{array}{l}\text { Rarely } \\
(\mathbf{\%})\end{array}$ & $\begin{array}{l}\text { Sometimes } \\
(\mathbf{\%})\end{array}$ & $\begin{array}{l}\text { Frequently } \\
\mathbf{( \% )}\end{array}$ \\
\hline Taking alcohol. & $77.2 \%$ & $11.4 \%$ & $5.7 \%$ & $5.7 \%$ \\
Smoking cigarette. & $91.9 \%$ & $2.4 \%$ & $2.4 \%$ & $3.3 \%$ \\
Joining to the night excessively & $78.9 \%$ & $11.4 \%$ & $6.4 \%$ & $3.3 \%$ \\
Eating much. & $60.1 \%$ & $17.9 \%$ & $17.9 \%$ & $4.1 \%$ \\
Getting irritable and yell at others & $57.7 \%$ & $25.2 \%$ & $11.4 \%$ & $5.7 \%$ \\
\hline
\end{tabular}

As it is outlined in table 5, the results disclosed that the majority of the students do not use negative stress coping strategies. Taking alcohol: as per the report presented in table 5, most of the participants have never been found take alcohol when they feel stressed. $11.4 \%$ of them have said that they rarely take alcohol when they are under the feeling of stress. In opposition to this, a small percentage of the respondents have disclosed that they sometimes $(5.7 \%)$ and most frequently $(5.7 \%)$ take alcohol to deal with their feeling stress. Smoking: a very high percentage of the participants $(91.9 \%)$ were found to never practice smoking as a stress coping technique. Join the nightclub and make fun: similarly, $78.9 \%$ of the respondents have reported that they never join the nightclub and make fun to deal with their feeling of stress. However, a few participants were also found rarely (11.4\%), sometimes 6.4\%) and frequently (3.3\%) use this unhealthy stress coping mechanism. Eating much: the majority of the participants have reported that they never $(60.1 \%)$, and rarely $(17.9 \%)$ overeat to cope with their stress level. The rest of them were, however, found some time $(17.9 \%)$ and most of the time (4.1\%) practicing overeating as a stress managing mechanism. Get irritable and yell at others: a high percentage of the respondents 
have informed that they never $(57.7 \%)$, rarely $(25.2 \%)$ get angry and shout at others when they feel stressed. Nevertheless, a small percentage of the respondents, on the other hand, have also said that they sometimes $(11.4 \%)$ and most frequently $(5.7 \%)$ practice this unhealthy stress coping mechanism.

\section{Coping strategies and Gender}

\section{Positive stress is coping strategies and gender.}

An independent sample t-test was conducted to compare the positive coping strategies scores for males and females. The result indicated that there is no statistically significant difference in the scores for males $(\mathrm{M}=26.92, \mathrm{SD}=5.34)$ and females $(\mathrm{M}=26.30, \mathrm{SD}=4.73) ; \mathrm{t}(121)=.68, \mathrm{p}=.50$, two-tailed. The size of the difference between the two means (mean difference $=.62,95 \% \mathrm{CI}:-1.19$ to 2.42 ) was minimal (Eta squared $=.003$ ). Besides, the assumption of homogeneity of variance was tested via Levene's F-test and no violation of assumption was occurred $\mathrm{F}(121)=.78, \mathrm{p}=.38$.

\section{Negative stress coping strategies and gender.}

Compared their mean values, the mean values for male participants $(\mathrm{M}=$ $7.61, \mathrm{SD}=2.83)$ was found to be slightly greater than their female counterparts $(\mathrm{M}=6.82, \mathrm{SD}=2.83)$. To test whether the difference was statistically significant, a t-test was calculated. The calculated t-test indicated that there is no significant difference in negative stress coping strategies scores for male and female students $\mathrm{t}(121)=1.61, \mathrm{p}=.11$, two-tailed. The magnitude of the difference between the means (mean difference $=.82,95 \% \mathrm{CI}$ : -.19 to 1.83 ) was small (eta squared $=.021$ ) as per the guideline for interpreting effect size proposed by Cohen (1988): 01 (small effect), 06 (moderate effect) and .14 (larger effect). Additionally, Levene' $\mathrm{F}$ test for equality of variance indicated no violation of assumption of homogeneity $\mathrm{F}(121)=1.26, \mathrm{p}=.26$.

\section{Discussion}

The primary purpose of the study was to identify and describe the stress coping strategies among the college students, and the finding of this study indicates that the students use more positive stress coping strategies than negative ones. Meaning that when the students feel stressed, they prefer to employ healthy stress managing techniques to deal with their feeling of stress. In line with this finding, in several studies, the majority of the college students were found to use healthy stress coping strategies (Kumar, 2011; Labrague et al., 2017; Lo, 2017). The reason why the majority of the students appear to practice acceptable and healthy coping style may rest on the broad context of sociocultural and spiritual values of the Eritrean society. Said differently, the people grow up and learn in a society where interdependence and religious belief 
are utmost. Several researchers also argue also that spirituality and social values enhance the practice of healthy coping strategies (Krok, 2008).

The finding of the present study also described that sleeping and taking enough rest, chatting and sharing a problem with parents, friends, and teachers, avoiding the stress causing situation and watching movies and entertaining comedies are the typical stress coping strategies used by college students. This result is consistent with the documented literature that prayers, meditation, and sleep (Thawabieh \& Qaisy, 2012), social (family) support (Siu \& Chang, 2011) and avoidance (Dyson \& Renk, 2006) are among the commonly practiced coping strategies among college students. However, as indicated by the present finding, the majority of participants reported that they show less practice of going to counselors. A similar supporting finding was reported by (Yeh, Inose, Kobori, \& Chang, 2001) showing that only a small proportion of the sample sought help from professionals or counselor. We assume that this may be attributed to lower awareness of the students on the role of guidance and counseling in helping and guiding them to cope with their college stress. Besides, although several studies such as Kim and McKenzie (2014) found college students to use physical activity as a means of coping with stress, in the present study, the majority of participants reported that they do not have the habit of doing regular exercises as a coping mechanism. The reason for this controversy may be differences in the personal behaviors and culture of the students concerning physical activity (Fagaras, Radu, \& Vanvu, 2015). Decreased interest in physical activity may also be due lack of time as a result of intensive academic activities (Ebben \& Brudzynski, 2008).

This research result showed that there is no any statistically significant difference in negative and positive stress coping strategies for both males and female students. However, in contrary to this finding, in a study conducted by Matud (2004), it was found that stress coping strategy was higher in boys than girls, indicating that female students use emotion-focused coping strategies and subsequently they experience a higher level of stress than their male counterparts. Besides, the present research generally found no statistically significant gender difference on the use of negative coping strategies. In line with the present study, Dyson and Renk (2006) found that there is no significant relationship between gender and unhealthy coping strategies. However, Pariat, Rynjah, and Kharjana (2014) found that regardless of the type of negative coping strategy, males are more inclined to use negative coping strategies than females.

\section{Limitations and Future research directions}

There are several limitations to the current study. As the study was primarily a descriptive study, it merely described the stress coping strategies in the college students without examining and controlling the factors that could potentially impact and confound the results. Also, the study was carried out in one college. Therefore, the findings may not be generalizable to other college students' population. Besides, data for the present study were obtained using a self-report questionnaire. Hence, as a common limitation for all survey studies, social desirability bias and lack of conscientious response in respondents may also limit 
the accuracy of the present findings. Another limitation of the study is the validity of the instrument. Experts' comments were used as a means of checking validity. However, as this may not be enough to understand and establish the psychometric properties of the instrument, this may influence the accuracy of the finding of the study. Bearing those limitations, future studies can develop the study to discover factors that predict to college students' coping style using a large sample. Future studies could also validate and establish the psychometric properties of the instrument using factor-analysis.

\section{Conclusion}

Majority of the College of Education students were found practicing more positive stress coping strategies than negative ones. The commonly practiced positive stress coping mechanism by the majority of the students are sleeping and taking enough rest, chatting with friends, sharing the problem with parents, friends or teachers: prayer, watching movies and entertaining comedies. This can possibly be common for the students due to the cultural background of the students. Eritreans fathers and mothers are very great in cultivating their children to meet their religious and cultural demands, in which they believe minimize risky coincidences. However, students were found having a poor practice regular exercise and contacting professionals like psychologists or counselors. As the college students stick too much to academics, they may fail to get time and engage in sports. The lack of visiting guidance and counselling centers definitely comes originates from the culture. The culture doesn't teach people to be open and express their feelings to others, especially to strangers.

The presents study found no statistically significant difference between gender and positive stress coping mechanisms. It is inferred that the students in the college level are matured to break the gender inequality and learn freely as they are equal. Thus, their level of education helps them stand great against inequality. Though the items used to measure the negative stress coping strategies were few (5 items), a very high percentage of the respondents $(91.9 \%)$ were found having a weak practice of unhealthy or unhealthy stress coping mechanisms like smoking, taking alcohol, overeating, getting angry and shouting at others. However, a small percentage of the respondents have also asserted that they rarely and sometimes use harmful stress coping approaches. This is merely the result of the parental treatment practices which is very helpful in pushing students to success. Irrespective of the type of undesirable stress coping strategy, male students were found to have slightly more often practice of unhealthy stress coping strategies than the female students. In this case, it seems that males are more exposed to risks behaviors than females, as females practices are more confined to household activities. 


\section{Recommendation}

Bearing the present study findings, educational implications and conclusion in mind, the researchers would like to present the following noteworthy recommendations.

> College or institution administration should work on improving the quality of the learning environment.

$>$ Concerned bodies of the institution should work making improvement on campus services like electricity and water supply, showers and latrines as these factors were found causing a high level of stress among the students.

$>$ Sufficient and quality campus recreation centers should be established.

$>$ Colleges should conduct regular communications and discussions (like seminars, meeting) with their students.

$>$ There should be practical guidance and counseling centers which provide professional service to the campus students.

$>$ Students in your learning process, you should cultivate an undaunted spirit. Once any stress-induced emotion arises, you should relax through an appropriate channel, examine their own problems, and seek solutions.

\section{Acknowledgment}

The article is financially supported by Finnish Church Aid (FCA) for publication.

\section{References:}

Adam, T. C., \& Epel, E. S. (2007). Stress, eating and the reward system. Physiology \& Behavior, 91(4), 449-458. doi: https://doi.org/10.1016/j.physbeh.2007.04.011

Allen, J., \& Holder, M. D. (2014). Marijuana Use and Well-Being in University Students. Journal of Happiness Studies, 15(2), 301-321. doi: 10.1007/s10902-013-9423-1

Anshel, M. (1996). Coping Styles Among Adolescent Competitive Athletes. The Journal of Social Psychology, 136(3), 311-323. doi: 10.1080/00224545.1996.9714010

Auerbach, M. S., \& Gramling, E. S. (1998). Stress Management: Psychological Foundations (1st ed.). Upper Saddle River, N.J: Prentice Hall.

Bandura, A. (1997). Self-Efficacy: The Exercise of Control. New York, US: W.H. Freeman and Company.

Bewick, B. M., Mulhern, B., Barkham, M., Trusler, K., Hill, A. J., \& Stiles, W. B. (2008). Changes in undergraduate student alcohol consumption as they progress through university. BMC Public Health, 8(1), 163. doi: 10.1186/1471-2458-8-163

Bode, C., de Ridder, D. T. D., Kuijer, R. G., \& Bensing, J. M. (2007). Effects of an Intervention Promoting Proactive Coping Competencies in Middle and Late Adulthood. The Gerontologist, 47(1), 42-51. doi: 10.1093/geront/47.1.42

Bodenmann, G., Perrez, M., Cina, A., \& Widmer, K. (2002). The effectivenessof a coping-focused prevention approach: A two-year longitudinalstudy. Swiss Journal of Psychology, 61(4), 195202. doi: $10.1024 / / 1421-0185.61 .4 .195$

Bottorff, J. L., Johnson, J. L., Moffat, B. M., \& Mulvogue, T. (2009). Relief-oriented use of marijuana by teens. Substance Abuse Treatment, Prevention, and Policy, 4(1), 7. doi: 10.1186/1747-597X$4-7$ 
Brougham, R. R., Zail, C. M., Mendoza, C. M., \& Miller, J. R. (2009). Stress, Sex Differences, and Coping Strategies Among College Students. Current Psychology, 28(2), 85-97. doi: 10.1007/s12144-009-9047-0

Chen, L., Zhong, M., Cao, X., Jin, X., Wang, Y., Ling, Y., . . Yi, J. (2017). Stress and Self-Esteem Mediate the Relationships between Different Categories of Perfectionism and Life Satisfaction. Applied Research in Quality of Life, 12(3), 593-605. doi: 10.1007/s11482-016-9478-3

Chenji, S. K., Rao, C. R., Sivanesan, S., Kamath, V., \& Kamath, A. (2018). Cross-sectional analysis of obesity and high blood pressure among undergraduate students of a university medical college in South India. Family Medicine and Community Health, 6(2), 63-69. doi: 10.15212/FMCH.2017.0134

Cohen, J. (1988). Statistical power analysis for the behavioral sciences. Hillsdale, N.J.: L. Erlbaum Associates.

Coiro, M. J., Bettis, A. H., \& Compas, B. E. (2017). College students coping with interpersonal stress: Examining a control-based model of coping. Journal of American College Health, 65(3), 177186. doi: $10.1080 / 07448481.2016 .1266641$

Dyson, R., \& Renk, K. (2006). Freshman adaptation to university life: Depressive symptoms, stress, and coping. Journal of Clinical Psychology, 62(10), 1231-1244. doi: doi:10.1002/jclp.20295

Ebben, W., \& Brudzynski, L. (2008). Motivations and Barriers to Exercise among College Students Journal of Exercise Physiology, 11(5), 1-11.

Ellison, C., Boardman, D. J., Williams, D., \& Jackson, S. J. (2001). Religious Involvement, Stress, and Mental Health: Findings from the 1995 Detroit Area Study. Social Forces, 80(1), 215-249. doi: $10.1353 /$ sof.2001.0063

Fabricatore, N. A., Handal, P., \& Fenzel, M. (2012). Personal spirituality as a moderator between stressors and subjective well-being. Journal of psychology and theolog, 28(3), 221-228. doi: 10.1177/009164710002800305

Fagaras, S.-P., Radu, L.-E., \& Vanvu, G. (2015). The Level of Physical Activity of University Students. Procedia - Social and Behavioral Sciences, 197, 1454-1457. doi: https://doi.org/10.1016/j.sbspro.2015.07.094

Field, A. (2009). Discovering statistics using SPSS (3rd ed.). London, Britain: SAGE.

Fox, K. (2004). The kleenexfor men crying game report: A study of men and crying. The Social Issues Research Centre. Retrieved from www.sirc.org/publik/Crying_Game.pdf.

Gaedke, G., Covarrubias Venegas, B., Simbrunner, P., \& Janous, G. (2012). Impact of Stress Factors on Part-Time College Students. International Journal for Cross-Disciplinary Subjects in Education, 3(2), 692-698. doi: 10.20533/ijcdse.2042.6364.2012.0098

Garthe, R. C., Griffin, B. J., Worthington, E. L., Goncy, E. A., Sullivan, T. N., Coleman, J. A., . . . Anakwah, N. (2017). Negative Interpersonal Interactions and Dating Abuse Perpetration: The Mediating Role of Dispositional Forgivingness. Journal of Interpersonal Violence, 33(15), 23112334. doi: $10.1177 / 0886260517714438$

Gravetter, F., \& Wallnau, L. (2014). Essentials of Statistics for the Behavioral Sciences (8th ed.). Belmont, CA: Wadsworth.

Honglin, C., Yu-Cheung, W., Mao-Sheng, R., \& Christie, G. (2009). Stress among Shanghai University Students: The Need for Social Work Support. Journal of Social Work, 9(3), 323-344. doi: $10.1177 / 1468017309334845$

Jex, M. S., Bliese, D. P., Buzzell, S., \& Primeau, J. (2001). The impact of self-efficacy on stressorstrain relations: Coping style as an explanatory mechanism. Journal of Applied Psychology, 86(3), 401-409. doi: 10.1037//0021-9010.86.3.401

Kadhiravan, S., \& Kumar, K. (2012). Enhancing stress coping skills among college students. Journal of Arts, Science \& Commerce, 3(4), 49-55. doi: Retrivied on 28/07/2018 from http://www.researchersworld.com/vol3/issue4/vol3_issue4_1/Paper_07.pdf

Kenney, S. R., DiGuiseppi, G. T., Meisel, M. K., Balestrieri, S. G., \& Barnett, N. P. (2018). Poor mental health, peer drinking norms, and alcohol risk in a social network of first-year college students. Addictive Behaviors, 84, 151-159. doi: https://doi.org/10.1016/j.addbeh.2018.04.012

Kim, J.-H., \& McKenzie, L. A. (2014). The Impacts of Physical Exercise on Stress Coping and Well- Being in UniversityStudents in the Context of Leisure. Health Education \& Behavior, 6, 2570-2580. doi: http://dx.doi.org/10.4236/health.2014.619296

Krok, D. (2008). The role of spirituality in coping: Examining the relationships between spiritual dimensions and coping styles. Mental Health, Religion \& Culture, 11(7), 643-653. doi: $10.1080 / 13674670801930429$

Kumar, R. (2011). Stress and Coping Strategies among Nursing Students. Nursing and Midwifery Research Journal, 7(4), 141-151. 
Labrague, L. J., McEnroe-Petitte, D. M., Gloe, D., Thomas, L., Papathanasiou, I. V., \& Tsaras, K. (2017). A literature review on stress and coping strategies in nursing students. Journal of Mental Health, 26(5), 471-480. doi: 10.1080/09638237.2016.1244721

Lazarus, R. S., \& Folkman, S. (1984). Stress, appraisal, and coping. . New York: Springer Publishing Company.

Lo, C.-F. (2017). Stress and Coping Strategies among Uni-versity Freshmen in Hong Kong: Valida-tion of the Coping Strategy Indicator. Psychology, 8(1254-1266). doi: https://doi.org/10.4236/psych.2017.88081

Lorant, V., Nicaise, P., Soto, V. E., \& d'Hoore, W. (2013). Alcohol drinking among college students: college responsibility for personal troubles. BMC Public Health, 13(1), 615. doi: 10.1186/14712458-13-615

Macgeorge, E. L., Samter, W., \& Gillihan, S. J. (2005). Academic Stress, Supportive Communication, and Health A version of this paper was presented at the 2005 International Communication Association convention in New York City. Communication Education, 54(4), 365-372. doi: $10.1080 / 03634520500442236$

Matud, M. P. (2004). Gender differences in stress and coping styles. Personality and Individual Differences, 37(7), 1401-1415. doi: https://doi.org/10.1016/j.paid.2004.01.010

Meda, S. A., Hawkins, K. A., Dager, A. D., Tennen, H., Khadka, S., Austad, C. S., . . Pearlson, G. D. (2018). Longitudinal Effects of Alcohol Consumption on the Hippocampus and Parahippocampus in College Students. Biological Psychiatry: Cognitive Neuroscience and Neuroimaging, 3(7), 610-617. doi: https://doi.org/10.1016/j.bpsc.2018.02.006

Misigo, B. L. (2015). Gender difference in the perceived level of stress and coping strategies among university students in Kenya: A case of public universities. International Academic Journal of Social Sciences and Education., 1(4), 44-52.

Misra, R., \& Castillo, L. (2004). Academic Stress Among College Students: Comparison of American and International Students7\% of doctoral degrees earned in the. International Journal of Stress Management, 11(2), 132-148. doi: 10.1037/1072-5245.11.2.132

Pardini, D., Lochman, J., \& Wells, K. (2004). Negative Emotions and Alcohol Use Initiation in HighRisk Boys: The Moderating Effect of Good Inhibitory Control. Journal of Abnormal Child Psychology, 32(5), 505-518. doi: 10.1023/B:JACP.0000037780.22849.23

Pariat, L., Rynjah, A., \& Kharjana, M. G. (2014). Stress Levels of College Students: Interrelationship between Stressors and Coping Strategies. Journal of Humanities and Social Science, 19(8), 4046. .

Pelletier, J. E., Lytle, L. A., \& Laska, M. N. (2015). Stress, Health Risk Behaviors, and Weight Status Among Community College Students. Health Education \& Behavior, 43(2), 139-144. doi: $10.1177 / 1090198115598983$

Pierceall, E. A., \& Keim, M. C. (2007). Stress and Coping Strategies Among Community College Students. Community College Journal of Research and Practice, 31(9), 703-712. doi: $10.1080 / 10668920600866579$

Qidwai, W., Tabassum, R., Hanif, R., \& Khan, F. H. (2009). Belief in prayers and its role in healing among family practice patients visiting a teaching hospital in Karachi, Pakistan. Pakistan Journal of Medical Science, 25(2), 182-189. doi: http://dx.doi.org/10.5001/omj.2010.30

Rheinberg, F., \& Engeser, S. (2018). Intrinsic Motivation and Flow. In J. Heckhausen \& H. Heckhausen (Eds.), Motivation and Action (pp. 579-622). Cham: Springer International Publishing.

Robotham, D., \& Julian, C. (2006). Stress and the higher education student: a critical review of the literature. Journal of Further and Higher Education, 30(2), 107-117. doi: $10.1080 / 03098770600617513$

Sasaki, M., \& Yamasaki, K. (2007). Stress coping and the adjustment process among university freshmen. Counselling Psychology Quarterly, 20(1), 51-67. doi: 10.1080/09515070701219943

Seiffge-Krenke, I., Weidemann, S., Fentner, S., Aegenheister, N., \& Poeblau, M. (2001). Coping with School-Related Stress and Family Stress in Healthy and Clinically Referred Adolescents. Journal of European Psychologist, 6(2), 123-132. doi: 10.1027//1016-9040.6.2.123

Shimazu, A., Okada, Y., Sakamoto, M., \& Miura, M. (2003). Effects of Stress Management Program for Teachers in Japan: A Pilot Study. Journal of Occupational Health, 45(4), 202-208. doi: $10.1539 /$ joh. 45.202

Singh, P. (2016). Bridging Social Group in Coping Psychological Problems. International Journal of Engineering Technology, Management and Applied Sciences, 4(1), 108-112. 
Siu, A. F. Y., \& Chang, J. F. (2011). Coping Styles and Psychological Distress among Hong Kong University Students: Validation of the Collectivist Coping Style Inventory. International Journal for the Advancement of Counselling, 33(2), 88-100. doi: 10.1007/s10447-011-9114-8

Tang, F., Byrne, M., \& Qin, P. (2018). Psychological distress and risk for suicidal behavior among university students in contemporary China. Journal of Affective Disorders, 228, 101-108. doi: https://doi.org/10.1016/j.jad.2017.12.005

Thawabieh, A. M., \& Qaisy, L. M. (2012). Assessing Stress among University Students. American International Journal of Contemporary Research, 2(2), 110-116.

Wang, S.-L., \& Wu, P.-Y. (2008). The role of feedback and self-efficacy on web-based learning: The social cognitive perspective. Computers \& Education, 51(4), 1589-1598. doi: https://doi.org/10.1016/j.compedu.2008.03.004

Waqas, A., Khan, S., Sharif, W., Khalid, U., \& Ali, A. (2015). Association of academic stress with sleeping difficulties in medical students of a Pakistani medical school: a cross sectional survey. PeerJ, 3, e840. doi: 10.7717/peerj.840

Weyandt, L. L., Janusis, G., Wilson, K. G., Verdi, G., Paquin, G., Lopes, J., . . Dussault, C. (2009). Nonmedical Prescription Stimulant Use Among a Sample of College Students: Relationship With Psychological Variables. Journal of Attention Disorders, 13(3), 284-296. doi: $10.1177 / 1087054709342212$

Yeh, C., Inose, M., Kobori, A., \& Chang, T. (2001). Self and coping among college students in Japan. Journal of College Student Development, 42(3), 242-256.

Zafar, S. N., Syed, R., Waqar S, Zubairi, A., Vaqar, T., Shaikh, M., . . . Saleem, S. (2008). Selfmedication amongst university students of Karachi: prevalence, knowledge and attitudes. Journal of Pakistan Medical Association, 58(4), 214-217 